\title{
\begin{tabular}{|c|l|}
\hline IV Simpósio Paranaense de Modelagem, & Artigo: \\
$\begin{array}{c}\text { Simulaçãoe Controle de Processos } \\
\text { ISSN : 1984-7521 }\end{array}$ & Páginas: $\mathbf{9 7}$ - 104
\end{tabular}
}

\section{ANÁLISE DOS FORMATOS GEOMÉTRICOS DE ANÉIS DEFLETORES INTERNOS EM ESCOAMENTO GÁS-SÓLIDO EM RISERS}

\author{
Eduarda Mueller, Julia Volkmann, Jonathan Utzig*, Henry França Meier \\ Laboratório de Fluidodinâmica Computacional (LFC) \\ Universidade de Blumenau - FURB, Blumenau - SC \\ E-mail para contato: jutzig@furb.br
}

Resumo - A estrutura “core-annulus” em escoamentos gás-sólido é caracterizada por uma região diluída no centro e uma região densa em partículas sólidas próxima às paredes. Anéis internos podem ser inseridos a fim de redirecionar o escoamento e reduzir o acúmulo da fase sólida nas paredes, por conseguinte evitando a distribuição irregular em relação à concentração preferencial de partículas. A partir da análise do coeficiente de dispersão para a fração volumétrica média de sólidos em três alturas de um trecho de riser e da perda de carga, o presente trabalho almeja analisar a influência de 7 formatos geométricos de anéis defletores internos sobre o escoamento gás-sólido em risers.

Palavras-chave: Anéis defletores. Escoamento gás-sólido. Coeficiente de dispersão. Perda de carga.

\section{Introdução}

O Craqueamento Catalítico Fluido (FCC) representa um importante processo na indústria petrolífera: converte, a partir de frações pesadas de hidrocarbonetos, produtos de maior valor agregado, como a gasolina. As reações químicas no FCC ocorrem no riser através do contato do gasóleo com partículas catalisadoras e o escoamento em tal reator possui comumente perfil core-annulus, caracterizado pelo acúmulo da fase sólida particulada nas paredes e uma região menos densa no centro do riser [1]. A heterogeneidade em relação à fração volumétrica resulta em uma pior conversão das reações, visto que há um contato menos eficaz entre a fase gasosa e a sólida, reduzindo tanto a transferência de calor quanto a de massa. Além disso, tal concentração pode induzir a geração de zonas quentes que favoreçam o craqueamento térmico, que leva à formação de coque e gases secos pouco valiosos.

A inserção de anéis defletores internos é realizada para redirecionar o escoamento das partículas de catalisador, e assim, deslocá-las para o centro do riser, originando maior homogeneidade na distribuição radial e axial da fase sólida. $\mathrm{O}$ ângulo de abertura do defletor, a espessura do anel, o espaçamento entre anéis, o número de anéis e a presença de um anel abaixo da entrada de catalisador são importantes variáveis que influenciam no escoamento [2,3]. A partir da análise estatística pelo desvio-padrão da fração volumétrica das fases e da análise visual de simulações numéricas, é possível determinar a influência das variáveis controladas em relação à distribuição de sólidos na seção transversal do riser [4].

Além das características relacionadas aos anéis, as condições operacionais atuam significativamente no perfil do escoamento. Impostos distintos parâmetros de operação, a região dos internos é caracterizada por baixa fração volumétrica e maior velocidade de gás [5]. Os anéis dispersam os sólidos da parede para a seção transversal, por conseguinte desenvolvem uma distribuição mais homogênea das partículas sólidas. Todavia, a inserção de tais dispositivos reduz a área interna do riser, podendo ocasionar aumento da perda de carga devido à maior dissipação viscosa [6], mas por outro lado a redução do inventário de sólidos pode também levar à redução da perda de carga.

O objetivo deste trabalho consiste em analisar, fundamentado na literatura, sete formatos geométricos de anéis defletores internos em risers e, através da fluidodinâmica

\section{4 e 15 de março de 2019 Curitiba - Paraná}


computacional (CFD), avaliar tanto a distribuição de partículas sólidas no reator quanto a perda de carga. $\mathrm{O}$ estudo referente ao grau de dispersão dos sólidos também tem como intuito determinar a posição mais apropriada de cada anel, sendo realizado em 3 alturas: $0,1 \mathrm{~m}, 1,0 \mathrm{~m}$ e 2,0 $\mathrm{m}$ a jusante do defletor.

\section{Modelagem Matemática e Condições Numéricas}

As simulações numéricas realizadas seguiram a abordagem euleriana-euleriana para representar o escoamento gás-sólido, através da mediação de Reynolds sobre as equações de Navier-Stokes e com modelo de turbulência k- $\omega$ SST (omitido para fins de brevidade), conforme a Tabela 1. A fase gasosa é tratada como incompressível, isotérmica e newtoniana. O comportamento tensorial da fase sólida é dado pela Teoria Cinética do Escoamento Granular (KTGF) na sua forma diferencial. A fim de garantir um custo computacional reduzido, a geometria axissimétrica dupla foi adotada para o riser (Fig. 1), realizando a simulação de cada formato geométrico com a inserção de apenas um anel em um trecho do equipamento. Testes para garantir a independência dos resultados em relação à malha numérica foram realizados, levando à escolha de uma discretização com 17604 nós, com atenção à concentração de nós próximos às paredes.

Tabela 1: Modelos matemáticos resolvidos no presente estudo

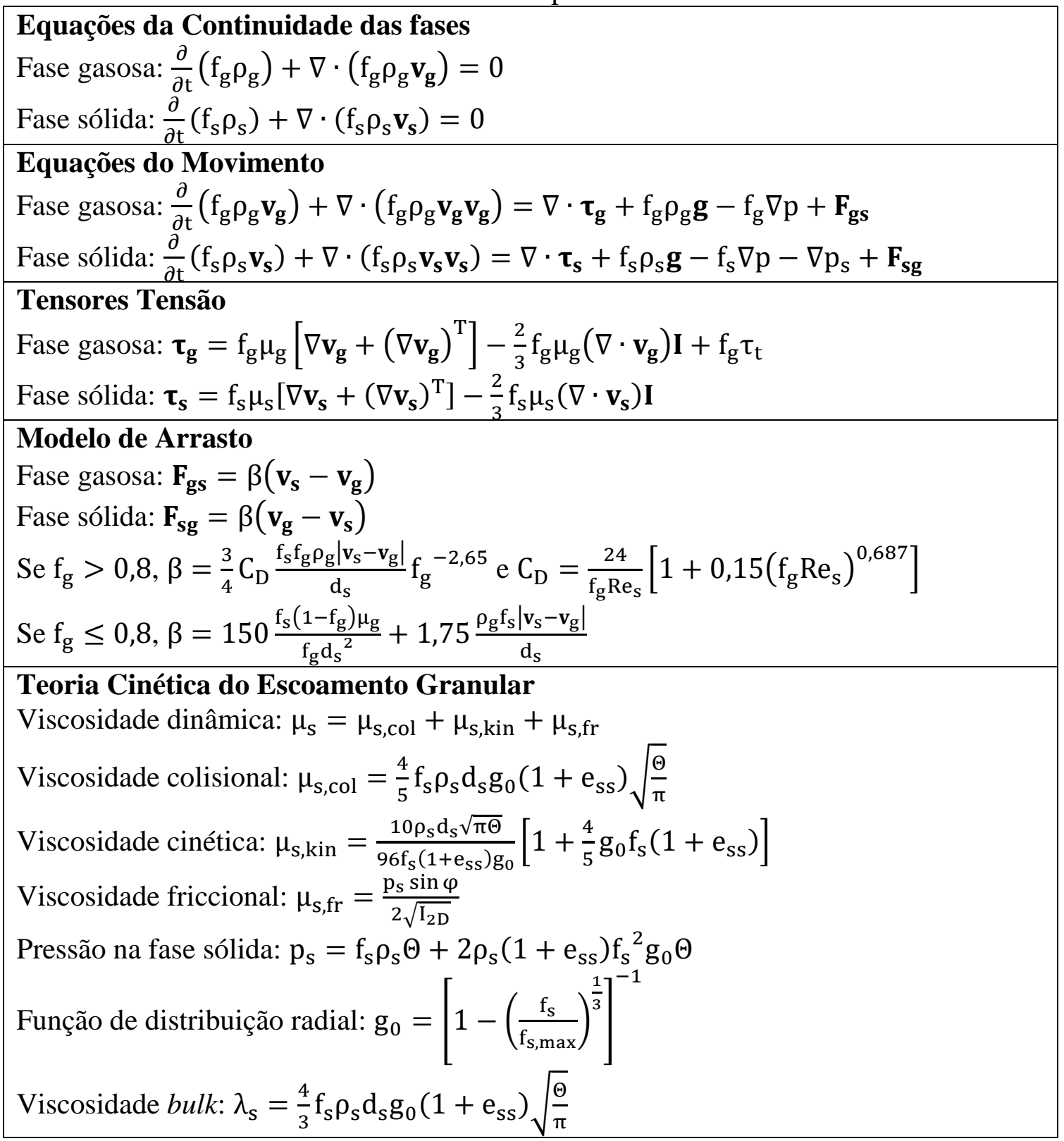


Temperatura Granular:

$$
\frac{3}{2}\left[\frac{\partial}{\partial \mathrm{t}}\left(\rho_{\mathrm{s}} \mathrm{f}_{\mathrm{s}} \Theta_{\mathrm{s}}\right)+\nabla \cdot\left(\rho_{\mathrm{s}} \mathrm{f}_{\mathrm{s}} \mathbf{v}_{\mathrm{s}} \Theta_{\mathrm{s}}\right)\right]=\left(-\mathrm{P}_{\mathrm{s}} \mathbf{I}+\boldsymbol{\tau}_{\mathrm{s}}\right): \nabla \mathbf{v}_{\mathrm{s}}+\nabla \cdot\left(\mu_{\mathrm{s}} \nabla \Theta_{\mathrm{s}}\right)-\gamma_{\Theta_{\mathrm{s}}}+\phi_{\mathrm{gs}}
$$

Dissipação de energia colisional: $\gamma_{\Theta_{\mathrm{s}}}=\frac{12\left(1-\mathrm{e}_{\mathrm{ss}}{ }^{2}\right) \mathrm{g}_{0}}{\mathrm{~d}_{\mathrm{s}} \sqrt{\pi}} \rho_{\mathrm{s}} \mathrm{f}_{\mathrm{s}}{ }^{2} \Theta_{\mathrm{s}}{ }^{3 / 2}$

Transferência de energia cinética entre as fases gasosa e sólida devido às flutuações de velocidade: $\phi_{\mathrm{gs}}=-3 \mathrm{k}_{\mathrm{gs}} \Theta_{\mathrm{s}}$

Parâmetros do modelo: $\mathrm{e}_{\mathrm{ss}}=0,9 ; \mathrm{f}_{\mathrm{s}, \max }=0,63$

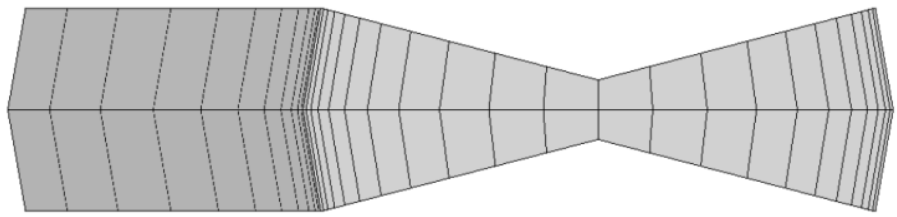

Entrada em Y

Riser axissimétrico

Figura 1 - Seção transversal da malha numérica pseudo-2D.

Através destas simulações de Fluidodinâmica Computacional (CFD, Computational Fluid Dynamics), resolveu-se o escoamento no riser sem anéis até identificar os campos estacionários e utilizá-los como condição de entrada nos casos com anéis, e posteriormente avaliar a redispersão de sólidos proporcionada pelos diferentes formatos de internos. Visto que o foco é analisar a influência dos internos sobre o escoamento core-annulus, a maior fração volumétrica de partículas sólidas foi deslocada para as paredes do trecho do riser, adotando um fluxo mássico de sólidos equivalente a $\mathrm{Gs}=8 \mathrm{~kg} /\left(\mathrm{m}^{2} \mathrm{~s}\right)$ na base. As simulações consideram ar atmosférico a $25^{\circ} \mathrm{C}$ e $1 \mathrm{~atm}$ como fase contínua e partículas de vidro, diâmetro médio de Sauter $\mathrm{d}_{\mathrm{p},[3,2]}=72 \mu \mathrm{m}$ e massa específica $\rho_{\mathrm{p}}=2500 \mathrm{~kg} / \mathrm{m}^{3}$. A velocidade do gás foi prédefinida na base do riser como $\overline{\mathbf{v}}_{\mathrm{g}}=7 \mathrm{~m} / \mathrm{s}$, os planos laterais receberam condição de simetria, nas paredes reais do riser a velocidade do gás é nula e as partículas têm deslizamento livre, enquanto no topo a saída recebe condição de gradiente de pressão nulo. $\mathrm{O}$ escoamento foi resolvido por $10 \mathrm{~s}$ após sua estabilização, com passo de tempo $\Delta \mathrm{t}=0,001 \mathrm{~s}$, sobre os quais foram gravadas médias das variáveis. Os termos advectivos receberam tratamento de segunda ordem. O modelo matemático foi resolvido pelo código comercial ANSYS Fluent 14.0.

A interferência dos defletores internos em relação ao escoamento gás-sólido foi examinada e ponderada de acordo com a homogeneidade de sólidos distribuídos radialmente no riser, analisando-a de acordo com o desvio padrão dessa variável através do Coeficiente de Dispersão $\left(\mathrm{C}_{\mathrm{V}}\right)$, conforme apresentado na Eq. 1:

$$
\mathrm{C}_{\mathrm{V}}=\frac{\sigma_{\mathrm{sd}}}{\mathrm{f}_{\mathrm{s}}}=\frac{\sqrt{\frac{\sum\left(\mathrm{f}_{\mathrm{si}}-\overline{\mathrm{f}}_{\mathrm{s}}\right)^{2}}{\mathrm{~N}}}}{\overline{\mathrm{f}_{\mathrm{s}}}}
$$

onde $\sigma_{\mathrm{sd}}$ representa o desvio padrão da fração volumétrica no plano, $\overline{\mathrm{f}}_{\mathrm{s}}$ equivale à média das amostras em relação à fração volumétrica e $\mathrm{N}$ é a quantidade total de amostras. É interessante salientar que um menor coeficiente de dispersão corresponde à uma amostra mais homogênea em relação à variável de estudo.

A uniformidade do fluxo multifásico na seção radial também pode ser estudada pelo Índice Radial de Não-uniformidade (RNI, Radial Nonuniformity Index), calculado a partir da razão entre o desvio padrão da fração volumétrica ponderada e o fator de normalização $\sigma_{\max }\left(f_{s}\right)$, como mostra a Eq. 2 [7]. Para um fluxo mais uniforme é esperado um menor valor de RNI, e vice-versa: 


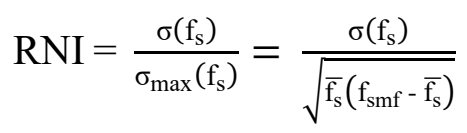

sendo $\mathrm{f}_{\mathrm{smf}}$ a máxima fração de sólidos possível.

Os formatos geométricos escolhidos para os anéis foram fundamentados em patentes da UOP LLC (formato trapezoidal), da Phillips Petroleum Company e da Shell Oil Company (formato triangular), além de estudos prévios do grupo de pesquisa (formato aerodinâmico) [8]. As geometrias trapezoidais tiveram como referência o modelo US 9,283,532 B2 [9], já para a triangular, baseou-se nas patentes 5,851,380 e US 6,596,242 B1 [10,11].

Os sete formatos de anéis defletores simulados, suas dimensões e nomenclaturas adotadas estão ilustrados na Fig. 2. O tamanho do defletor foi definido obedecendo a relação 1:10 entre a espessura do anel e o diâmetro interno do riser [9]. Assim, a espessura máxima dos internos foi estipulada em $10 \mathrm{~mm}$. Para cada tipo de anel há um ângulo de entrada e um de saída, por conseguinte existem alturas distintas dos defletores, resultando na menor altura para a geometria do Triângulo isósceles $(10,18$ $\mathrm{mm})$ e a maior, para a do Trapézio $10^{\circ}(80 \mathrm{~mm})$.

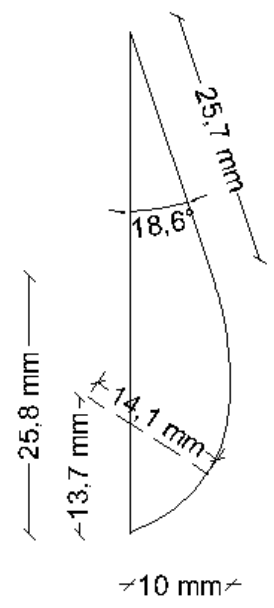

(a)

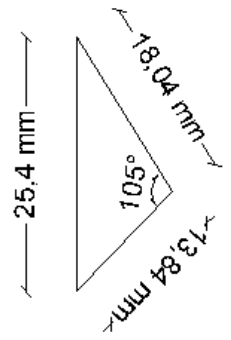

(b)

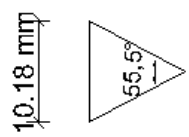

(c)

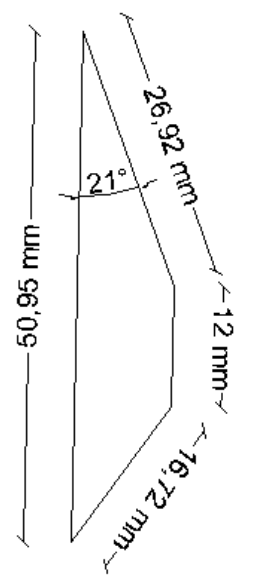

(g)

(d)

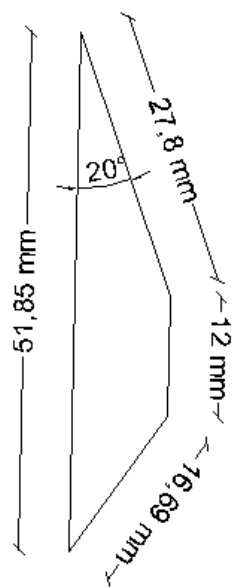

(e)

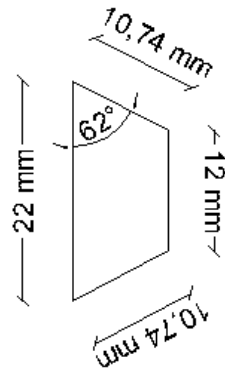

(f)

Figura 2 - Desenhos dimensionais e nomenclaturas dos anéis defletores simulados: (a) Aerodinâmico; (b) Triângulo Phillips; (c) Triângulo Isósceles; (d) Trapézio $15^{\circ}$; (e) Trapézio $20^{\circ}$; (f) Trapézio Isósceles; (g) Trapézio Modificado. 


\section{Resultados e Discussão}

A atuação dos anéis defletores testados foi analisada por meio da perda de carga causada no escoamento, do coeficiente de dispersão avaliado em relação à fração volumétrica de partículas sólidas e dos campos da fração volumétrica. As perdas de carga referentes aos sete tipos de internos são apresentadas na Tabela 2. Os valores se referem à variação total de pressão que ocorreu no trecho de riser anterior ao anel (2 m), no anel defletor e no trecho posterior ao anel (3 m com a inclusão do anel). As simulações resultaram em valores muito próximos para as condições operacionais adotadas - sendo que o maior e o menor valor referente à quantidade de energia perdida durante o escoamento está vinculada à geometria do Aerodinâmico $(298,41 \mathrm{~Pa})$ e do Trapézio modificado $(255,09 \mathrm{~Pa})$, respectivamente - tal que a maior diferença de resultados obtida foi igual a 43,32 $\mathrm{Pa}$. O fato de o formato aerodinâmico ter apresentado a maior perda de carga é coerente, visto que foi o que apresentou maior dissipação das regiões concentradas de sólidos promovida pelo redirecionamento do fluxo para o centro do riser - representado na Fig. 5 -, ocasionando maior transferência de quantidade de movimento entre as fases e, assim, maior gasto energético. $\mathrm{O}$ trecho de riser sem defletor desenvolve um escoamento com $235 \mathrm{~Pa}$ de perda de carga, isso significa que um único anel com o formato Trapézio Modificado eleva o gasto energético em cerca de $55 \mathrm{~Pa}$, o Trapézio $15^{\circ}$ em $28 \mathrm{~Pa}$ e o Aerodinâmico, em $63 \mathrm{~Pa}$.

Tabela 2 - Perdas de cargas referentes aos tipos de internos.

\begin{tabular}{c|c}
\hline Geometria & Perda de carga (Pa) \\
\hline Sem anel & 235,00 \\
\hline Aerodinâmico & 298,41 \\
\hline Trapézio $15^{\circ}$ & 262,84 \\
\hline Trapézio $20^{\circ}$ & 260,27 \\
\hline Trapézio isósceles & 265,74 \\
\hline Trapézio modificado & 255,09 \\
\hline Triângulo Phillips & 267,18 \\
\hline Triângulo isósceles & 273,44 \\
\hline
\end{tabular}

Para mensurar o grau de dispersão dos sólidos proporcionado por cada interno, o Coeficiente de Dispersão para a fração volumétrica média de sólidos foi calculado para três alturas do riser $(0,1 \mathrm{~m}, 1 \mathrm{~m}$ e $2 \mathrm{~m}$ após o início do defletor) e os valores obtidos são apresentados na Fig. 3. Da mesma forma, a Fig. 4 apresenta o Índice Radial de Nãouniformidade. É possível verificar em todos os casos que quanto mais próximo dos defletores, maior é o coeficiente, e que essa variável decresce gradativamente quanto mais distante dos internos. Tal comportamento é previsto, pois os internos redirecionam para o centro o escoamento de partículas que estavam previamente concentradas próximas à parede do riser. Dada a similaridade entre as Figs. 3 e 4, percebe-se que os dois parâmetros são adequados para tal análise.

A geometria do Trapézio Modificado foi proposta baseada nas dimensões geométricas do Aerodinâmico, visando uma maior facilidade de construção e instalação em unidades industriais. O modelo trapezoidal apresentou coeficiente de dispersão maior nas três alturas em relação ao aerodinâmico que é, portanto, mais favorável entre os dois. Todavia, é constatado que quanto mais distante do interno for feita a obtenção de dados, menor será a diferença entre os coeficientes de dispersão desses dois formatos. 
Com o menor coeficiente de dispersão nas alturas mais distantes do anel, o trapézio com ângulo de saída igual a $15^{\circ}$ representou a geometria mais adequada, destacando-se por obter uma variação praticamente duas vezes melhor do que a segunda melhor geometria. Entretanto, é interessante notar que $0,1 \mathrm{~m}$ a jusante do interno, o modelo aerodinâmico obteve melhor resultado, visto que possibilita que as partículas sólidas sejam dissipadas mais rapidamente na seção transversal.

As geometrias triangulares obtiveram coeficientes de variação muito similares quando analisadas $2 \mathrm{~m}$ a jusante do anel no riser. Nas alturas mais próximas ao anel, o triângulo isósceles resultou em uma fração volumétrica um pouco mais homogênea. Já para a medição posterior, o Triângulo Phillips obteve uma menor variabilidade dos dados em comparação ao isósceles. Por sua vez, o Trapézio $20^{\circ}$ e o Trapézio Isósceles também obtiveram perfis análogos referentes à homogeneidade da distribuição de sólidos na seção transversal do trecho do equipamento. Apresentando a maior diferença na altura de $4 \mathrm{~m}$, o modelo com ângulo de $20^{\circ}$ retratou resultados um pouco mais satisfatórios do que a geometria trapezoidal com ângulo de $62,25^{\circ}$.

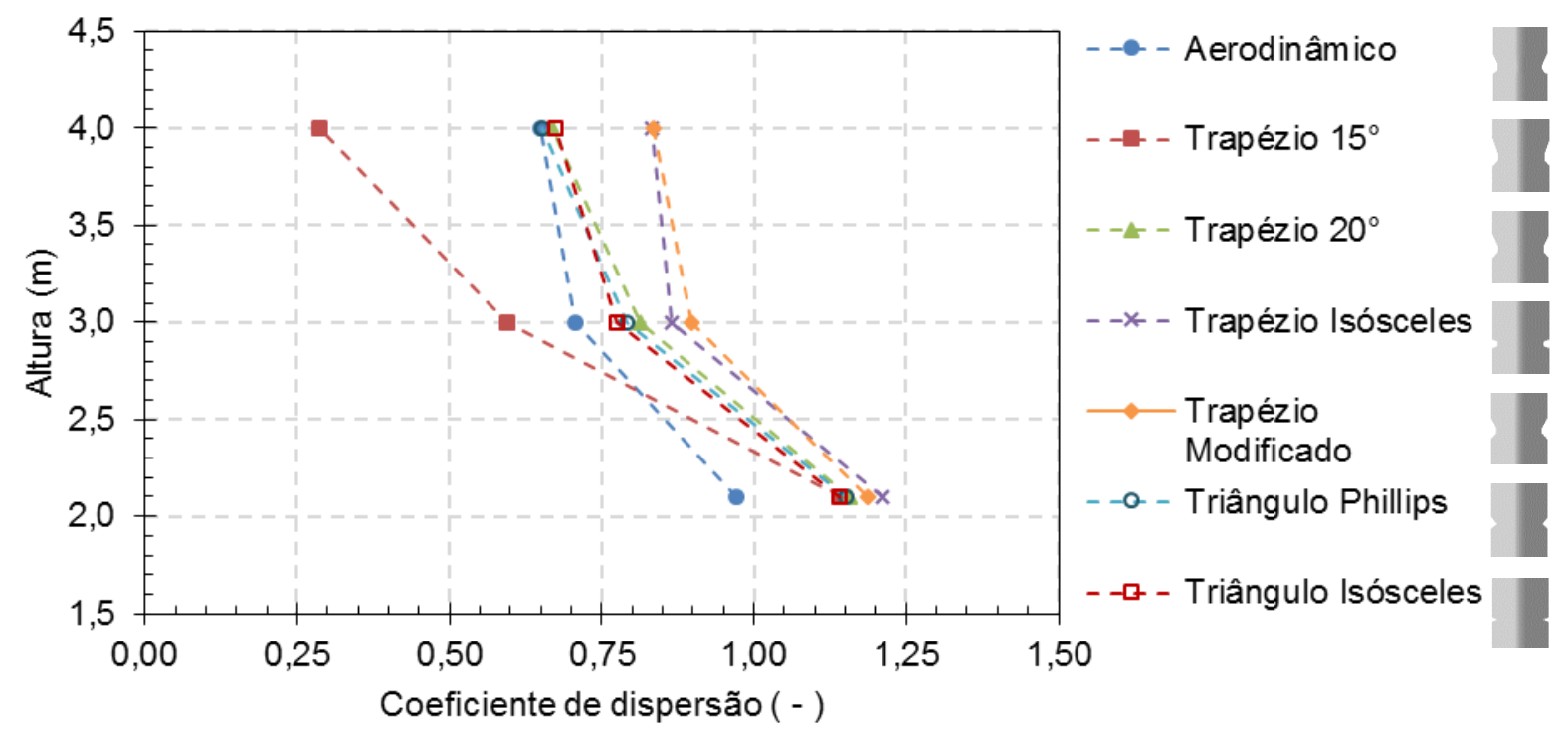

Figura 3 - Coeficiente de dispersão em diferentes alturas do riser para cada defletor.

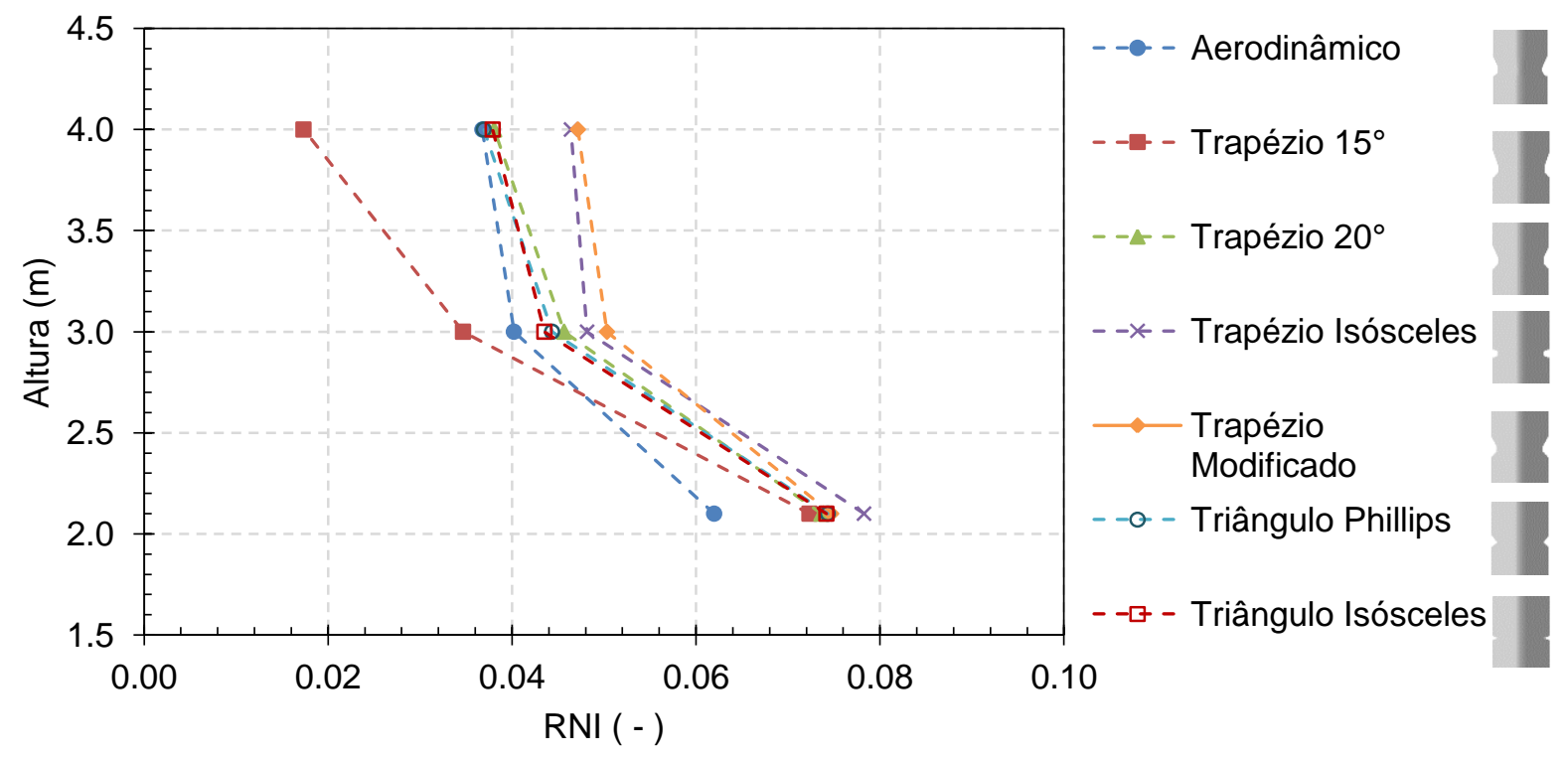

Figura 4 - Índice Radial de Não-uniformidade em diferentes alturas do riser para cada defletor. 
Todos os tipos de formatos geométricos obtiveram campos de concentração muito parecidos, conforme apresentado na Fig. 5, sendo a fase sólida do escoamento direcionada para o centro do riser, reduzindo a fração volumétrica presente nas extremidades radiais do equipamento. De fato, a maior fração volumétrica de sólidos presente próxima às paredes a montante dos internos, deixa de ocorrer após estes. No entanto, pode-se observar regiões com baixa fração volumétrica logo após determinados anéis nas condições operacionais adotadas. Esse perfil representa o descolamento da camada limite do escoamento, responsável por causar zonas de recirculação do escoamento, potencializando demasiadamente a erosão sobre o anel, bem como a geração de pontos quentes e sobrecraqueamento de gasóleo. Tal incoveniente pode ser evitado a partir da redução do ângulo de saída do anel, caso dos anéis Trapézio $15^{\circ}$, Trapézio $20^{\circ}$ e Trapézio Modificado.

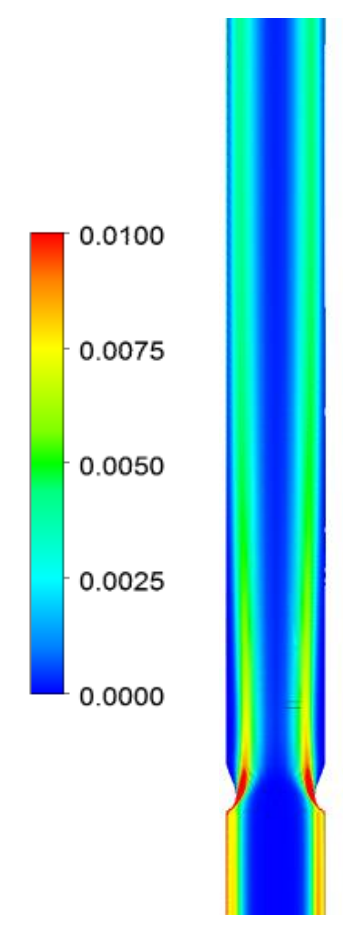

(a)

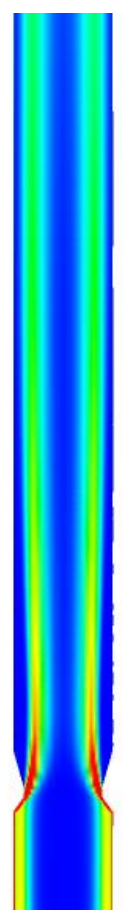

(b)

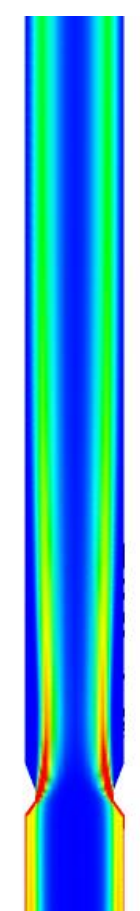

(c)

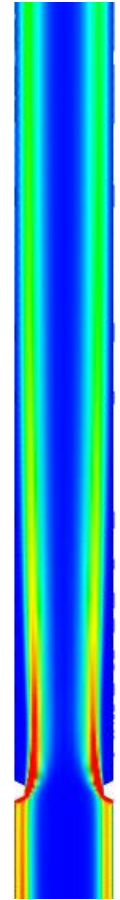

(d)

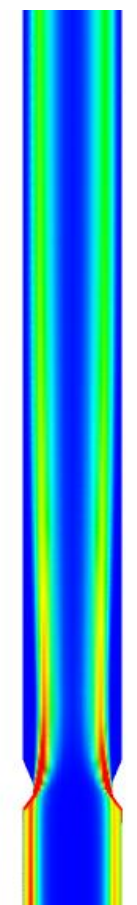

(e)

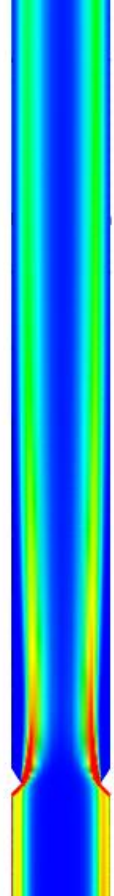

(f)

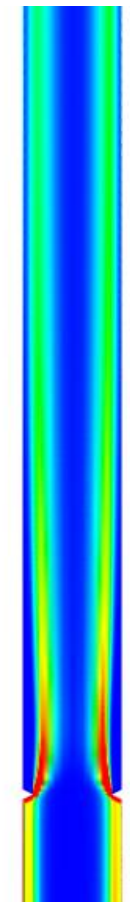

(g)

Figura 5 - Campo de fração volumétrica conforme os tipos de internos: (a) Aerodinâmico, (b) Trapézio $15^{\circ}$, (c) Trapézio $20^{\circ}$, (d) Trapézio Isósceles, (e) Trapézio Modificado, (f) Triângulo Phillips e (g) Triângulo Equilátero.

\section{Conclusão}

A capacidade de redirecionar o escoamento - os sólidos saindo das paredes e sendo dispersos para o centro do riser, assim favorecendo a distribuição das partículas na seção transversal - foi coerentemente simulada para cada anel defletor e analisada de acordo com o coeficiente de dispersão. A perda de pressão ocasionada pela redução da área disponível devido à inserção do interno também foi ponderada para todas as geometrias em estudo.

Dentre os sete formatos geométricos analisados, o Aerodinâmico e o Trapézio $15^{\circ}$ foram os que obtiveram melhor desempenho. A altura de interesse no riser é a variável que definirá a geometria mais adequada, portanto para as condições operacionais adotadas e se a variação de coeficiente de dispersão for linear, há melhor redispersão dos sólidos causada pela geometria aerodinâmica até $0,7 \mathrm{~m}$ acima do anel, após esta altura a redispersão ocasionada pelo formato trapezoidal possui maior homogeneidade. Todavia vale ressaltar que por promover maior dissipação da fase 
sólida, o modelo aerodinâmico ocasiona maior perda de carga, ou seja, maior gasto energético.

\section{Agradecimentos}

Os autores agradecem o suporte de Petróleo Brasileiro S.A. - PETROBRAS (termo de cooperação 5850.0103010.16.9).

\section{Referências}

[1] R.P. Brito. Análise Numérica da Influência de Defletores sobre o Escoamento GásSólido em Risers de FCC via Fluidodinâmica Computacional, Dissertação de Mestrado, Universidade Estadual de Campinas, 2018.

[2] F.J. Sanchez Careaga; C. Briens; F. Berruti; J. McMillan; M. Gray. Agglomerate behavior in a recirculating fluidized bed with sheds: Effect of ring baffles. Particuology. 2018, v. 38, p. 143-151.

[3] V. Rossbach; J. Utzig; R.K. Decker; D. Noriler; C. Soares; W.P. Martignoni; H.F. Meier. Gas-solid flow in a ring-baffled CFB riser: Numerical and experimental analysis. Powder Technology. 2019, v. 345, p. 521-531.

[4] V. Rossbach; R.K. Decker; D. Noriler; J. Utzig; H.F. Meier. Análise Numérica do uso de Anéis Defletores Internos sobre o Escoamento Gás-Sólido em Risers de FCC. In: Congresso Brasileiro de Sistemas Particulados - ENEMP, São Carlos, 2015.

[5] B. Chalermsinsuwana; T. Samruamphianskun; P. Piumsomboon. Effect of operating parameters inside circulating fluidized bed reactor riser with ring baffles using CFD simulation and experimental design analysis. Chemical Engineering Research and Design. 2014, v. 92, p. 2479-2492.

[6] V. Rossbach; R.K. Decker; J. Utzig; H.F. Meier. Análise numérica de um riser de CFB com anéis defletores na região de entrada, in: Anais do Congresso Brasileiro de Engenharia Química - COBEQ, Florianópolis, 2016, v. 1.

[7] J. Zhu; S.V. Manyele. Radial Nonuniformity Index (RNI) in Fluidized Beds and Other Multiphase Flow Systems. The Canadian Journal of Chemical Engineering. 2001, v. 79, p. 203-213.

[8] V. Rossbach; J. Utzig; R.K. Decker; D. Noriler; H.F. Meier. Numerical gas-solid flow analysis of ring-baffled risers. Powder Technology. 2016, v. 297, p. 320-329.

[9] R.L. Mehlberg; M.S. Sandacz. Segmented baffle system for a riser. US no 9,283,532 B2, 2016.

[10] J.W. Wells. Process and apparatus for fluidized catalytic cracking of a hydrocarbon feed. US n ${ }^{\circ} 5,851,380,1998$.

[11] H.W.A. Dries. Reactor riser of a fluidized-bed catalytic cracking plant. US $\mathrm{n}^{\mathrm{o}}$ 6,596,242 B1, 2003. 